\title{
On the Global and Localised Corrosion Behaviour of the AA2524-T3 Aluminium Alloy Used as Aircraft Fuselage Skin
}

\author{
Jéferson Aparecido Moreto ${ }^{a}$, Luciana Sgarbi Rossino ${ }^{b}$, Waldek Wladimir Bose Filho ${ }^{c}$, \\ Cláudia Eliana Bruno Marino ${ }^{d}$, Miguel da Conceição Ferreira ${ }^{e}$, Maryna Taryba ${ }^{e}$, \\ João Carlos Salvador Fernandes ${ }^{e, f}$ \\ ${ }^{a}$ Instituto de Ciências Exatas, Naturais e Educação, Universidade Federal do Triângulo Mineiro \\ (UFTM), Av. Doutor Randolfo Borges Júnior, 38064200, Uberaba, MG, Brasil \\ ${ }^{b}$ Universidade Federal de São Carlos - UFSCar, Rodovia João Leme dos Santos, Km 110, Bairro do \\ Itinga, 18.052-780, Sorocaba, SP, Brasil \\ 'Departamento de Engenharia de Materiais, Universidade de São Paulo, Av. Trabalhador São-carlense, \\ 400, 13566590, São Carlos, SP, Brasil \\ ${ }^{d}$ Departamento de Engenharia Mecânica, Universidade Federal do Paraná (UFPR), Av. Cel. Francisco \\ H. dos Santos, 230, 81531990, Jardim das Américas, Curitiba, PR, Brasil \\ ${ }^{e}$ Centro de Química Estrutural - CQE, Instituto Superior Técnico, Universidade de Lisboa, 1049-001, \\ Lisboa, Portugal \\ ${ }^{f}$ Departamento de Engenharia Química, Instituto Superior Técnico, Universidade de Lisboa, 1049-001, \\ Lisboa, Portugal
}

Received: April 15, 2018; Revised: October 22, 2018; Accepted: November 20, 2018

The aim of this work was to study the corrosion process of new aluminium alloy AA2524-T3 (Solution Heat Treated and Cold Worked), which is a promising substitute of the base line AA2024-T3 for aircrafts fabrication, by global and localised techniques in sodium chloride medium $\left(0.05 \mathrm{~mol} \mathrm{~L}^{-1}\right.$ $\mathrm{NaCl}$ ). The open circuit potential results revealed a stochastic evolution of pitting events and to the resulting variations in the ratio of passive/active areas and/or cathode/anode, which may be related to the presence of different types of intermetallics. The cyclicvoltammetry showed that the corrosion potential $\left(\mathrm{E}_{\text {corr }}\right)$ and the pit nucleation potential $\left(\mathrm{E}_{p i t}\right)$ values are quite similar (approximately $-0.525 \mathrm{~V}$ ). The results of EIS show that the corrosion rate is quite stable, with no tendency to increase or decrease for longer immersion periods. The results of SVET were in agreement with the results obtained by EIS technique, showing strong anodic activity on the surface with no repassivation along the whole immersion time. Besides, corrosion process led to significant surface degradation after $24 \mathrm{~h}$.

Keywords: Galvanic coupling, Intermetallics, Pitting, EIS, SVET.

\section{Introduction}

Applications of Al alloys increase day by day, with great emphasis in the areas of transportation, civil construction, packaging and energy transportation ${ }^{1,2}$. Al alloys have become attractive due to their low cost, low density, mechanical and corrosive properties ${ }^{3,4}$. As described by Eskin ${ }^{5}$ in commercial 2xxx series aluminium alloys, $\mathrm{Cu}$ and $\mathrm{Mg}$ are the main alloying elements with small amount of $\mathrm{Si}$ and other minor elements as $\mathrm{Zn}, \mathrm{Mn}$, Ti and $\mathrm{Fe}$. The $\mathrm{Cu}$ alloying element provides one of the most widely used mechanisms for the strengthening ${ }^{6}$. According to the American Society for Metals ${ }^{2}$ the alloys of the $2 \mathrm{xxx}$ series are particularly suitable for structural parts that require a high strength-to-weight ratio and are used in the manufacture of aircraft fuselages, aircraft wings and parts needing a good resistance to temperatures below $150{ }^{\circ} \mathrm{C}$. However, as described by Queiroz et al. ${ }^{7}$ and Bonfils-Lahovary et al. ${ }^{8}$, aluminium alloys have a very

*e-mail jeferson.moreto.uftm@gmail.com complex microstructure due to heterogeneities leading to an increase of localised corrosion.

In order to improve the durability of the aircrafts, the aeronautical industry has been constantly working on development of new advantageous aluminium alloys ${ }^{9}$. The AA2524-T3 (Solution Heat Treated and Cold Worked) alloy produced by ALCOA may be used as fuselage skin material and represents a potential replacement for the AA2024 alloy, widely used by the aircraft industry ${ }^{9}$. Recent publications showed that the fatigue behaviour of AA2524-T3 aluminium alloy is dependent on experimental conditions (e.g. applied stress, loading rate, etc.) as well as sample orientation ${ }^{10,11}$. However, susceptibility to corrosion of AA2524-T3 alloy requires additional studies and the effect of the intermetallics (IMs) on the pitting corrosion of this alloy is still not fully understood.

Studies developed by Birbilis et al ${ }^{12,13}$ confirm that the electrochemical characteristics of IMs vary significantly in terms of corrosion potential, disintegration, oxygen reduction and dissolution reactions. As mentioned by Boag et al ${ }^{14}$ the 
IMs particles can be anodically or cathodically polarized with respect to the $\mathrm{Al}$ matrix, being preferentially corroded or inducing corrosion of the nearby matrix, respectively. In a previous work ${ }^{12}$, we studied the corrosion resistance of two novel alloys developed for aircraft industry (AA2198-T851 and 7081-T73511) to that presented by the alternative base alloys (AA2524-T3 and 7050-T7451, respectively). Regarding to $2 \mathrm{xxx}$ series Al alloys, the results confirmed that AA2198-T851 might show a superior corrosion performance compared to AA2524-T3 and the localised corrosion is related to the existence of IMs particles.

In this paper, the global and localised corrosion resistance of the AA2524-T3 aluminium alloy has been investigated by immersion test in $0.05 \mathrm{~mol} \mathrm{~L}^{-1} \mathrm{NaCl}$ solution. It is important to note that the present manuscript is complementary to the results obtained previously ${ }^{15}$ and reveals more details on the corrosion behaviour of the AA2524-T3 alloy used as fuselage skin material. For this purpose, the open circuit potential (OCP), potentiodynamic polarization (PP), cyclic potentiodynamic polarization, electrochemical impedance spectroscopy (EIS) and scanning vibrating electrode techniques (SVET) were performed.

\section{Material e Methods}

For the present investigations, the AA2524-T3 aluminium alloy (produced by ALCOA) was used in the "as received" condition. Table 1 lists the chemical composition of its major elements. Specimens of AA2524-T3 aluminium alloy were wet ground using abrasive papers from $800^{\#}$ to $4000^{\#}$. Prior to testing, they were degreased with propanol and carefully rinsed with distilled water. The morphology and composition of the alloy surface were assessed by scanning electron microscopy (SEM) before and after the corrosion tests, using an analytical FEG-SEM JEOL 7001F equipped with an Oxford light elements EDS detector.

The open circuit potential $\left(\mathrm{E}_{\text {ocp }}\right)$ of the samples was monitored during $3600 \mathrm{~s}$. Cyclic potentiodynamic polarization curves were recorded according to the ASTM G61-86

Table 1. Composition of the aluminium alloys (wt \%).

\begin{tabular}{lc}
\hline Elements & AA2524-T3 \\
\hline $\mathrm{Cu}$ & $3.84(4.0-4.5)$ \\
$\mathrm{Si}$ & $0.04(0.06 \mathrm{max})$ \\
$\mathrm{Fe}$ & $0.06(0.12 \mathrm{max})$ \\
$\mathrm{Mg}$ & $1.312(1.2-1.6)$ \\
$\mathrm{Mn}$ & $0.56(0.45-0.9)$ \\
$\mathrm{Ti}$ & $0.029(0.1 \max )$ \\
$\mathrm{Zn}$ & $0.01(0.15 \max )$ \\
$\mathrm{Cr}$ & $\mathrm{ND}(0.05 \mathrm{max})$ \\
$\mathrm{Al}$ & Balance
\end{tabular}

OBS: measured and (nominal) values.

ND: unidentified standard ${ }^{16}$ in the positive direction at a scan rate of $0.6 \mathrm{~V} \mathrm{~h}^{-1}$. As described by the ASTM G61-86 ${ }^{16}$ standard the onset of localised corrosion is usually marked by a rapid increase of the anodic current at potentials below the oxygen-evolution potential. When the current reaches $5 \mathrm{~mA} \mathrm{~cm}^{-2}$, the scanning direction is reversed. The test was concluded when negative values of the current were again recorded.

EIS spectra were obtained for AA2524-T3 aluminium alloy in the frequency range from $66 \mathrm{kHz}$ to $10 \mathrm{mHz}$, using a sinusoidal perturbation of $10 \mathrm{mV}$ (rms). In the present study, the spectra were obtained at $20 \mathrm{mV}$ negative to $\mathrm{E}_{\text {corr? }}$, in order to avoid non-linearity problems related with the occurrence of pitting at the corrosion potential ${ }^{17}$. The EIS measurements were performed in triplicate after $1,3,8,12$, $24,48,120$ and $168 \mathrm{~h}$ of immersion. The consistency of the impedance data and compliance to the validation criteria for these measurements was assessed through the use of KK transforms. For EIS data fitting, the ZView2C software was used. All the above electrochemical experiments were conducted in a naturally aerated solution of $0.05 \mathrm{~mol} \mathrm{~L}^{-1} \mathrm{NaCl}$ at $25 \pm 1{ }^{\circ} \mathrm{C}$, using a classical three-electrode configuration: the AA2524-T3 aluminium alloy as working electrode with an exposed area of $0.38 \mathrm{~cm}^{2}$, a saturated calomel reference electrode $\left(\mathrm{Hg} / \mathrm{Hg}_{2} \mathrm{Cl}_{2}, \mathrm{KCl}_{\text {sat }}\right)$ and a platinum auxiliary electrode.

The SVET tests were performed up to $24 \mathrm{~h}$ of immersion in a $0.05 \mathrm{~mol} \mathrm{~L}^{-1} \mathrm{NaCl}$ naturally aerated solution at room temperature, using a SVET system from Applicable Electronics Inc., controlled by the ASET software (Sciencewares, Inc.). To perform the measurements, the sample was glued to a holder and the exposed area (a square of approximately $0.6-1 \mathrm{~mm}^{2}$ ) was delimited by insulating the remaining surface using a mixture of beeswax and colophony. The visual appearance of the exposed area was continuously assessed with a microscopic video system with 140 times magnification. Measurements were performed in a $26 \times 26$ grid generating 676 data points. An insulated Pt-Ir probe with platinum black deposited on a spherical tip was used as vibrating electrode. The diameter of the sensing probe tip was $18 \mu \mathrm{m}$. The probe was placed $100 \mu \mathrm{m}$ above the surface, vibrating in 2 perpendicular planes, vertical $(Z)$ and horizontal $(X)$. The vibration frequencies of the probe were $124 \mathrm{~Hz}(\mathrm{Z})$ and $325 \mathrm{~Hz}(\mathrm{X})$. The measuring step has varied from 26 to $40 \mu \mathrm{m}$, depending of the size of the surface exposed to solution.

\section{Results e Discussion}

The dimension, type, and distribution of IMs particles are very important factors that affect the mechanical and corrosion-resistance performance of AA2524-T3 aluminium alloy. The microstructure of the AA2524-T3 alloy consists of a solid solution of $\mathrm{Al}$ and dispersion of incoherent particles in the matrix. Two types of IMs were found: $\mathrm{T} 1(\mathrm{Al}, \mathrm{Cu}$, $\mathrm{Mn}$ and $\mathrm{Fe}$ ) and incoherent precipitates $\mathrm{T} 2(\mathrm{Al}, \mathrm{Cu}, \mathrm{Mg})$ as 

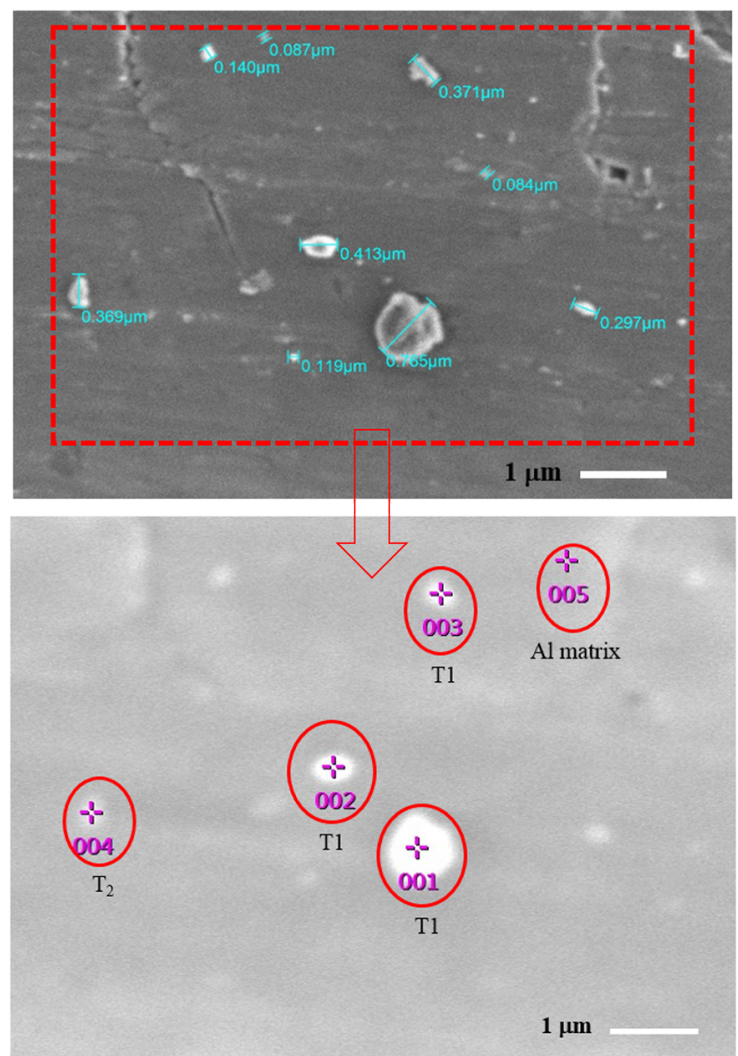

Figure 1. SEM observation of the 2524-T3 aluminium alloy before the electrochemical tests.

can be seen in Figure 1. The knowledge of the intermetallic compounds present in the AA2524-T3 alloy is extremely important since the corrosion resistance of aluminium alloys depends on their composition metal heterogeneities and on the medium or exposure conditions. These IMs usually cause localized corrosion such as pitting corrosion, due to the electrochemical potential difference between the IMs and the matrix. A detailed study of the IM compounds present in the AA2524-T3 alloy are in line with the previous work presented elsewhere ${ }^{9,15,18-19}$.

As reported by Srivatsan ${ }^{20}$, the microstructure of the AA2524-T3 aluminium alloy is fully recrystallized, presenting elongated and flattened grains. The EDS spectra used for the determination of the IMs compositions are not shown. Zheng et al. ${ }^{21}$ studied the behaviour of fatigue crack initiation and propagation in AA2524-T3 alloy. According to those authors, the SEM observation demonstrated that a large number of second phase particles parallel to the rolling direction can be found in the alloy. With the help of Energy-dispersive X-ray spectroscopy (EDS) analysis the same authors have obtained the chemical composition of these particles, consisting of some large particles containing $\mathrm{Al}, \mathrm{Cu}, \mathrm{Fe}, \mathrm{Mn}$ and smaller particles containing $\mathrm{Al}, \mathrm{Cu}$ and $\mathrm{Mg}$. These precipitates usually cause localised corrosion such as pitting corrosion and intergranular corrosion, due to the electrochemical potential difference between the precipitates and the matrix.

A representative curve of the open circuit potential (OCP) evolution with the immersion time for the AA2524-T3 aluminium alloy is presented in Figure 2 (a). The dependence of potential with time is linked to the stochastic evolution of pitting events and to the resulting variations in the ratio of passive/active areas and/or cathode/anode, which may be related to the presence of different types of intermetallics ${ }^{[15]}$. Gamboni et al. ${ }^{[22]}$ studied the corrosion behaviour of AA2524-T3 aluminium alloy in $3.5 \% \mathrm{NaCl}$ solution $(0.6$ $\mathrm{mol} \mathrm{L} \mathrm{L}^{-1}$ ), showing that the corrosion potential of this alloy is $-0.634 \mathrm{~V}$. In the present work, the open circuit potential of AA2524-T3 aluminium alloy is approximately -0.525 $\mathrm{V}$ after $3600 \mathrm{~s}$ of immersion and just before the cyclic voltammetry test. This observation is consistent with other investigations performed in $\mathrm{Al}$ alloys, taking into account the lower chloride concentration used. Figure 2 (b)shows a low magnification optical microscopy image of the surface after the open circuit potential test, where a large number of pits can be observed, providing valuable information on the on the nature of the corrosion process.

Figure 3 (a)presents the characteristic cyclic voltammetric curve for the 2524-T3 aluminium alloy in $0.05 \mathrm{~mol} \mathrm{~L}^{-1} \mathrm{NaCl}$ aqueous solution and Figure 3 (b) the magnified area for determining the pit nucleation potential $\left(\mathrm{E}_{p i t}\right)$. Figure 3 (c) shows the optical micrograph after the test. The corrosion potential $\left(\mathrm{E}_{c o r r}\right)$ and $\mathrm{E}_{p i t}$ values are approximately equal. It is important to mention the $\mathrm{E}_{p i t}$ was obtained from the extrapolation of the linear portion of the ascending curve. Almost no passive plateau can be observed in the anodic domain, suggesting growth of pits with the surge of current. According to Szklarska-Smialowska ${ }^{23}$ when the films formed on the surfaces of aluminium alloys are exposed to $\mathrm{Cl}^{-}$ions, fractures occur at specific points, leading to pits. Buchheit et al. ${ }^{24}$ studied the pit nucleation potential exhibited by simulated intermetallics with various compositions. The obtained values were compared with the experimental values observed for the AA2024-T3 aluminium alloy. The author verified that a part of the IMs exhibited a potential lower than the alloy, concluding that the beginning of pitting corrosion of the alloy is probably associated with the selective dissolution of the IMs.

Since the passive film is broken, the process of dissolution/ corrosion is initiated, causing the increase of the current density. When the current reaches $5 \mathrm{~mA} \mathrm{~cm}^{-2}$, the scanning direction was reversed and in this region it is possible to observe the presence of hysteresis as the current density in the cathodic direction is higher than in the anodic direction. Although an inflexion of the curve is noticed at approximately $-0.53 \mathrm{~V}$, characteristic of possible repassivation of the active pits, no passive plateau is observed in this reverse region, indicating that a complete repassivation was not achieved. For a more concentrated electrolyte $(0.6 \mathrm{M})$ the pitting 


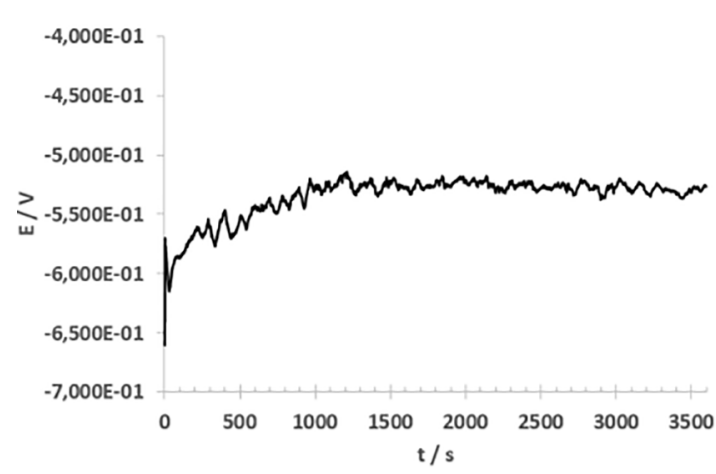

(a)

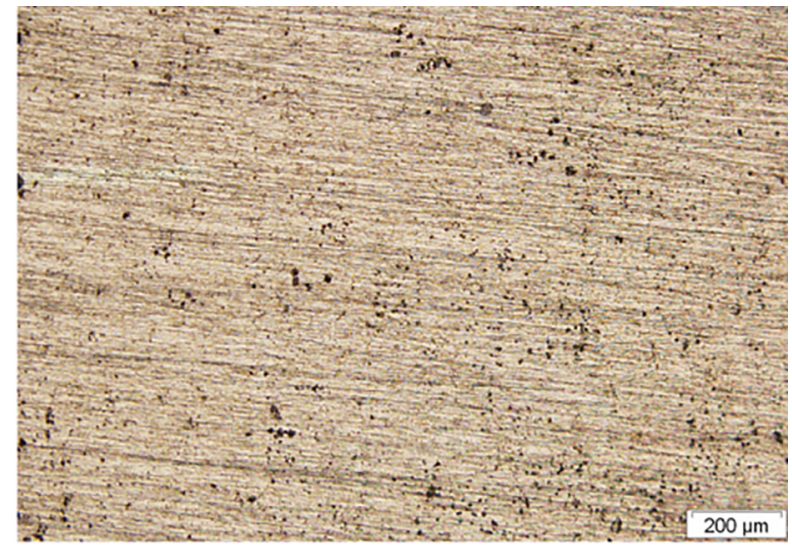

(b)

Figure 2. (a) Open circuit potential curve of the AA2524-T3 aluminium alloy in aerated $0.05 \mathrm{~mol} \mathrm{~L}^{-1} \mathrm{NaCl}$ aqueous solution and (b) image of AA2524-T3 aluminium alloy by optical microscopy of surface after the open circuit potential test.

(a)

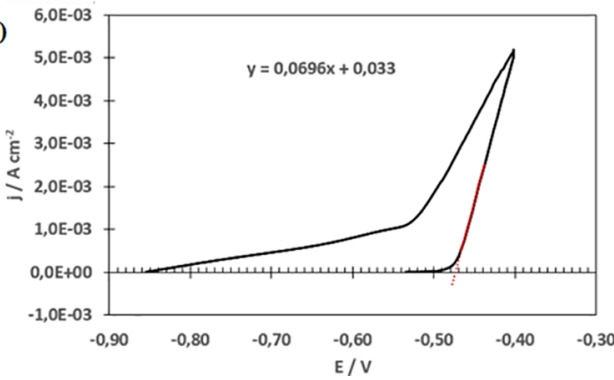

(b)

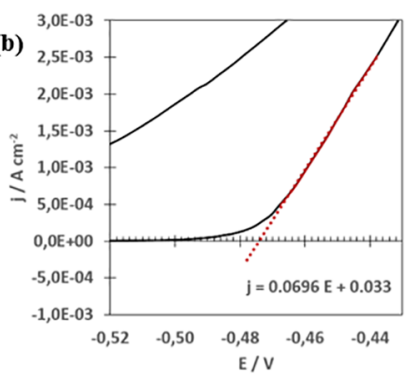

(c)

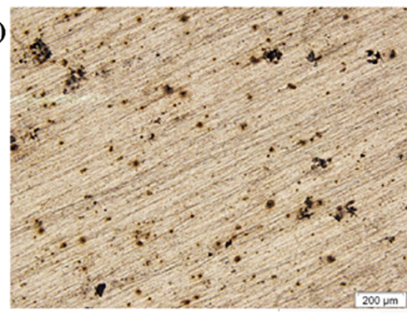

Figure 3. (a) Cyclic potentiodynamic polarization curve of the AA2524-T3 aluminium alloy in aerated $0.05 \mathrm{~mol} \mathrm{~L}^{-1} \mathrm{NaCl}$ aqueous solution, (b) the magnified area for determining the pit nucleation potential $\left(\mathrm{E}_{p i t}=-0.474 \mathrm{~V}\right)$ and (c) image of AA2524-T3 aluminium alloy by optical microscopy of surface after the cyclic potentiodynamic polarization test.

potential was around $-0.63 \mathrm{~V}^{22}$. In Figure 3 (c),obtained by optical microscopy, it is possible to notice pitting corrosion.

SEM observation of the AA2524-T3 aluminium alloy after the OCP tests (Figure 4 (a)) revealed the presence of IMs whose elemental chemical composition was obtained through EDS analysis. Probably, the intermetallic shown in the micrograph is $\mathrm{T}_{1}(\mathrm{Al}, \mathrm{Cu}, \mathrm{Fe}, \mathrm{Mn})$. Figure 4 (b)presents the SEM observation after the PP tests. As can be seen, the presence of cathodic $\mathrm{T}_{2}(\mathrm{Al}, \mathrm{Cu}, \mathrm{Mg}$ ) promotes galvanic coupling, leading to the preferential dissolution (trenching) of the nearby matrix and formation of preferential sites for pitting initiation. The micrograph also presents defects and pitting in the surface of material.

EIS spectra were obtained for, at least, three samples of AA2524-T3 aluminium alloy after 1, 3, 8, 12, 24, 48, 120 and $168 \mathrm{~h}$ of exposure to the $0.05 \mathrm{~mol} \mathrm{~L}^{-1} \mathrm{NaCl}$ solution. Figure 5 (a)shows a comparison of the data obtained for alloy AA2524-T3 in this work and the data obtained by Moreto et al ${ }^{12}$ in $0.6 \mathrm{~mol} \mathrm{~L}^{-1} \mathrm{NaCl}$ aqueous solution after $24 \mathrm{~h}$ exposure. As can be seen, in both conditions the electrochemical behaviour of the AA2524-T3 alloy suggested two time constants, one at high frequencies and a second time constant at lower frequencies. According to Ferreira et al ${ }^{25}$ the second time constant is due to localised corrosion processes. As reported by Yasakau et $\mathrm{al}^{26}$ localised corrosion is a very complex process involving many heterogeneous and homogeneous reactions. Ma et al. ${ }^{27}$ studied the localised corrosion of AA2099-T83 Al - Li alloys, concluding that the localised corrosion associated with low-copper containing Al-Fe-Mn-Cu- (Li) particles is typified with trenching around the particles. In the present case, the characteristic time constant at low frequencies is clearly due to pitting corrosion, which is also evident in Figure 5 (b), where the evolution of potential with time during the first hour shows the typical transients of this type of corrosion. The main difference between the results in the two different solutions is the higher impedance moduli at high frequencies observed in $0.05 \mathrm{~mol} \mathrm{~L}^{-1} \mathrm{NaCl}$ solution, due to the lower conductivity of this solution. The impedance moduli at low frequencies are very similar, indicating a low resistance to localised corrosion in both cases.

The equivalent circuit depicted in Figure 6 (a), based on the circuit originally presented by Jüttner ${ }^{28}$ may be used to describe the behaviour of this kind of materials. It is composed by $R_{\Omega}$, ohmic resistance of the electrolyte, a loop $\mathrm{R}_{\mathrm{ox}}-\mathrm{C}_{\mathrm{ox}}$, respectively the resistance and capacitance of 


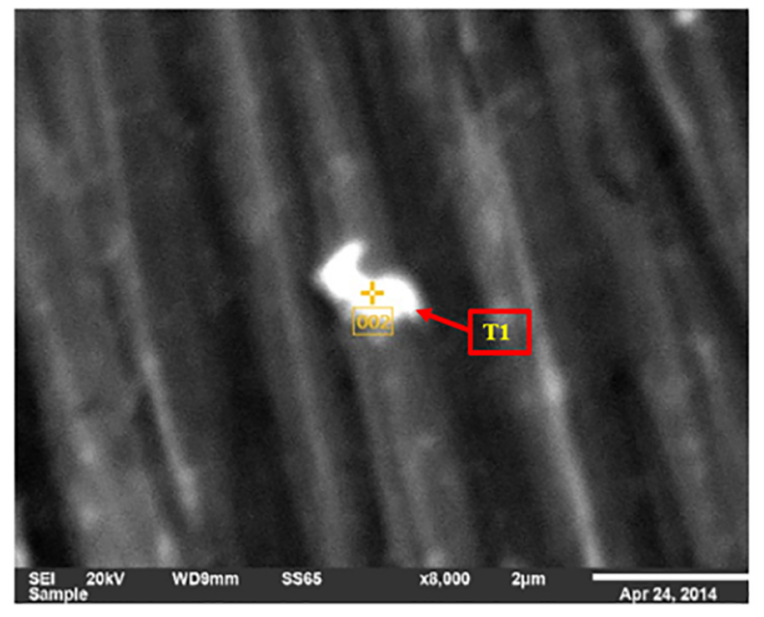

(a)

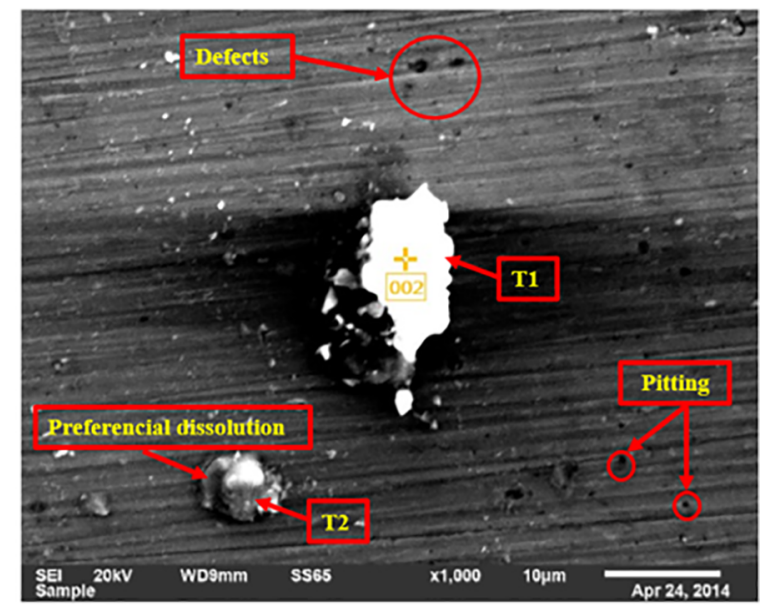

(b)

Figure 4. (a) SEM observation of the AA2524-T3 aluminium alloy after the open circuit potential tests and (b) SEM observation of the AA2524-T3 aluminium alloy after the potentiodynamic polarization tests.

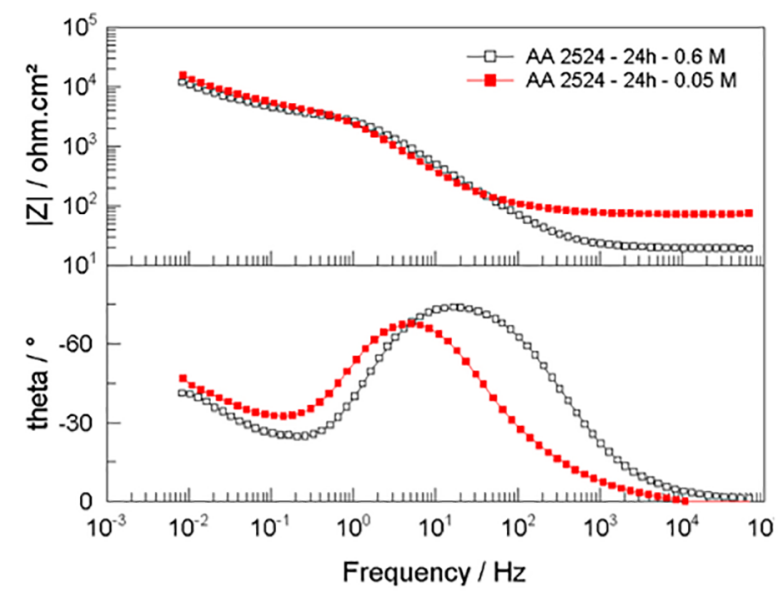

(a)

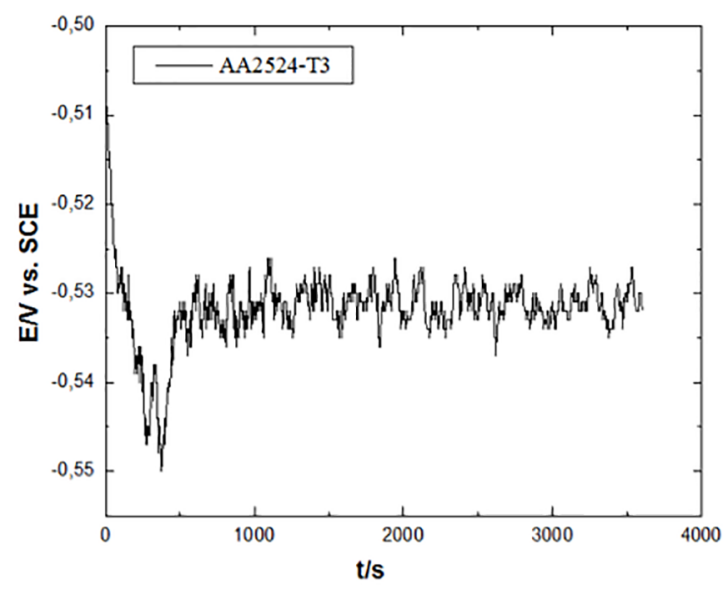

(b)

Figure 5. (a) Comparison of the data obtained for alloy AA2524-T3 in this work ( $\mathrm{mol} \mathrm{L}^{-1}$ ) and the data obtained by Moreto et al ${ }^{12}$ in 0.6 mol L-1 $\mathrm{NaCl}$ solution after $24 \mathrm{~h}$ exposure and (b) evolution potential with time for the first hours of tests.

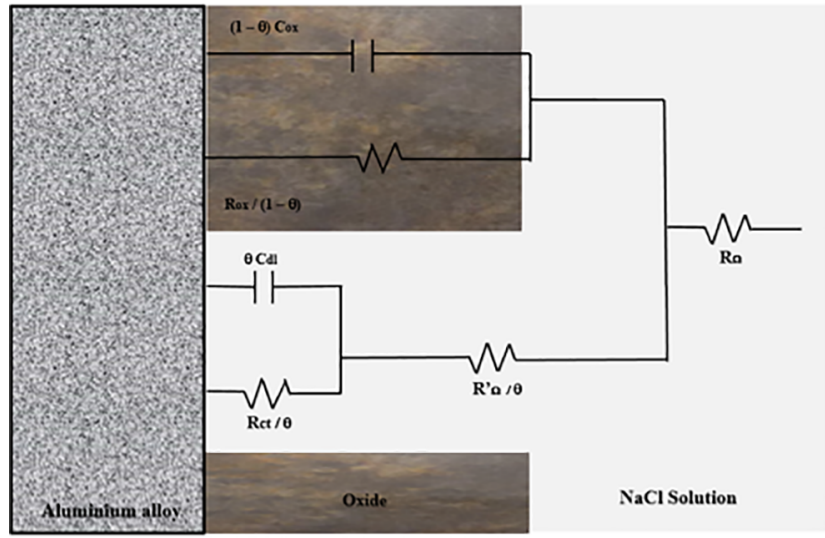

(a)

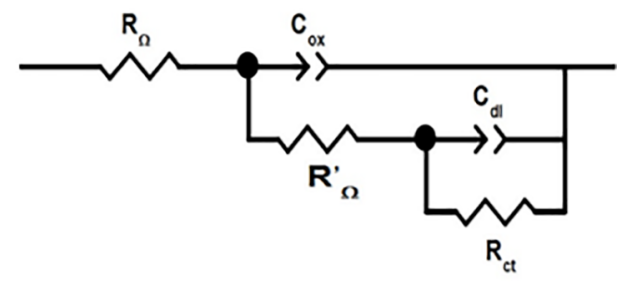

(b)

Figure 6. (a) Schematic representations of the model 25 and (b) proposed equivalent circuit. 
the oxide layer, and a contribution of the pitting/trenching processes taking place at the particles as a $\mathrm{R}_{\mathrm{ct}}-\mathrm{C}_{\mathrm{dl}}$ network that represents the charge transfer reaction corresponding to localised corrosion and the capacitance of the double layer, added to the additional resistance of the electrolyte inside the pit/trench, $\mathrm{R}_{\Omega}$. The measured values $\mathrm{R}_{\mathrm{ox}}, \mathrm{C}_{\mathrm{ox}}$, $\mathrm{R}_{\Omega}{ }_{\Omega}, \mathrm{R}_{\mathrm{ct}}$ and $\mathrm{C}_{\mathrm{dl}}$ depend on the pitted area fraction $\theta$ and so they correspond to $\mathrm{R}^{*}{ }_{\text {ox }} /(1-\theta),(1-\theta) \mathrm{C}^{*}{ }_{\mathrm{ox}}, \mathrm{R}^{*}{ }_{\Omega} / \theta, \mathrm{R}^{*}{ }_{\mathrm{ct}} / \theta$ and $\theta \mathrm{C}^{*}{ }_{\mathrm{dl}}$, where $\mathrm{R}^{*}{ }_{\mathrm{ox}}, \mathrm{C}^{*}{ }_{\mathrm{ox}}, \mathrm{R}^{*}{ }_{\Omega}, \mathrm{R}^{*}{ }_{\mathrm{ct}}$ and $\mathrm{C}^{*}{ }_{\mathrm{dl}}$ are the intrinsic values of each parameter. As $\mathrm{R}_{\text {ox }} /(1-\theta)$ tends to be extremely high, not allowing for any conduction of electrons across the oxide film, this circuit element is usually removed from the equivalent circuit, that transforms into the one proposed by Mansfeld and Kendig ${ }^{[29]}$, depicted in Figure 6 (b).

Table 2 shows the average values of the EIS parameters of AA2524-T3 aluminium alloy in $0.05 \mathrm{~mol} \mathrm{~L}^{-1} \mathrm{NaCl}$ solution. The values of $\mathrm{R}_{\Omega}$ show a constant decrease with time, explained by the evaporation of water in the cell during the $168 \mathrm{~h}$ of tests, leading to an increase of concentration and, thus, conductivity with time. The analysis of $\mathrm{C}_{\mathrm{dl}}$ values shows a tendency towards higher values as the immersion time increases. This could be attributed to the increase of the pitted area, $\theta$, as $\mathrm{C}_{\mathrm{dl}}$ is, in fact, the product of an intrinsic capacitance $\mathrm{C}^{*}$ by the pitted to total surface ratio. However, such an increase of the pitted area would in principle lead to a decrease in the resistance $\mathrm{R}_{\mathrm{ct}}$, which is not observed. An alternative explanation may be related with the extreme $\mathrm{pH}$ values expected inside the pits. In fact, it is commonly accepted that the intrinsic interfacial capacitance tends to increase as the local environment inside the pits turns more aggressive.

According to Ahmed ${ }^{30}$, as the $\mathrm{pH}$ decreases below the $\mathrm{pH}_{\mathrm{pzc}}$ of aluminium oxide, the adsorption of anions will lead to an exponential increase of the capacitance. This effect was also studied by Fernandes ${ }^{31}$ in $\mathrm{W}$-implanted aluminium. Finally, the evolution of the pits or trenches may be affected by the formation of corrosion products that block the surface, justifying the decrease in the capacitance values for very long immersion times. Concerning the values of $\mathrm{R}_{\mathrm{tc}}$, they show an initial increase, followed by stabilization in the range of $60-70 \mathrm{k} \Omega \mathrm{cm}^{2}$.
The results of SVET measurements are presented in Figure 7, where (a) and (b) correspond to optical micrographs at the beginning and after $24 \mathrm{~h}$ of immersion, respectively, and (c), (d) and (e) depict the current density distributions after $1 \mathrm{~h}, 14 \mathrm{~h}$ and $20 \mathrm{~h}$. As it can be seen in Figure 7 (c), the sites of anodic activity were detected from the very beginning of immersion and were continuously developing along the immersion time (Figure 7 (d) and (e)). The maximum values of cathodic current density remained stable from one scan to the other during the whole period of measurements (Figure 7 (c)-(e)).No passivation was observed. After $24 \mathrm{~h}$ of immersion significant degradation of surface was evident (Figure 7 (b)). The results demonstrate that the zone of the preferential formation of pits correlates to the zone recognized by SVET as a cathodic. Shi et al in ${ }^{32}$ conclude that self-dissolution of $S$ phase plays prevalent role in corrosion process resulting in trenching of aluminium matrix around S-phase intermetallics and formation of the pits.

\section{Conclusions}

An experimental investigation of the corrosion behaviour of industrially important AA2524-T3 aluminium alloy, used in aircraft fabrication, was performed in diluted $0.05 \mathrm{~mol} \mathrm{~L}^{-1}$ $\mathrm{NaCl}$ solution. Two conclusions were obtained in this work:

1. The pitting resistance of the alloy is considered low and quite similar to those obtained in $0.6 \mathrm{~mol} \mathrm{~L}^{-1}$ (or $3.5 \%$ ) $\mathrm{NaCl}$ solution, so even a reduced chloride concentration promoted pitting;

2. The evolution of the process with time was assessed, showing that the corrosion rate is quite stable, with no tendency to increase or decrease for longer immersion periods. The results of SVET were in agreement with the results obtained by general electrochemical techniques, demonstrating no passivation along the whole immersion time. Besides, corrosion process led to significant surface degradation after $24 \mathrm{~h}$.

\section{Acknowledgements}

The authors gratefully acknowledge the Department of Mechanical Engineering - Federal University of Paraná

Table 2. Average values of the EIS parameters of AA2524-T3 aluminium alloy obtained by Zview 2 software.

\begin{tabular}{ccccccc}
\hline Sample & $\begin{array}{c}\text { Time } \\
(\mathrm{h})\end{array}$ & $\begin{array}{c}\mathrm{R}_{\Omega} \\
\left(\Omega . \mathrm{cm}^{2}\right)\end{array}$ & $\begin{array}{c}\mathrm{C}_{\mathrm{ox}} \\
\left(\mu \mathrm{F} . \mathrm{cm}^{-2}\right)\end{array}$ & $\begin{array}{c}\mathrm{R}_{\Omega}^{\prime} \\
\left(\mathrm{k} \Omega . \mathrm{cm}^{2}\right)\end{array}$ & $\begin{array}{c}\mathrm{C}_{\mathrm{dl}}{ }^{-2} \\
\left(\mu \mathrm{F} . \mathrm{cm}^{-2}\right)\end{array}$ & $\begin{array}{c}\mathrm{R}_{\mathrm{ct}} \\
\left(\mathrm{k} \Omega . \mathrm{cm}^{2}\right)\end{array}$ \\
\hline 1 & 92.54 & 40.3 & 8.52 & 113 & 31.85 \\
\multirow{3}{*}{$\mathbf{A A 2 5 2 4}$} & 3 & 92.95 & 58.3 & 6.13 & 258 & 49.90 \\
& 8 & 91.08 & 66.6 & 5.57 & 645 & 64.46 \\
& 12 & 80.57 & 71.1 & 4.49 & 856 & 67.41 \\
& 24 & 75.30 & 72.8 & 5.29 & 632 & 64.28 \\
& 48 & 73.93 & 91.6 & 5.92 & 393 & 48.65 \\
& 120 & 75.26 & 148 & 6.38 & 348 & 64.85 \\
& 64.59 & 179 & 6.13 & 339 & 69.08 \\
\hline
\end{tabular}




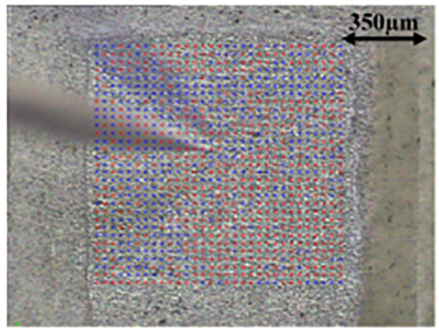

(a)

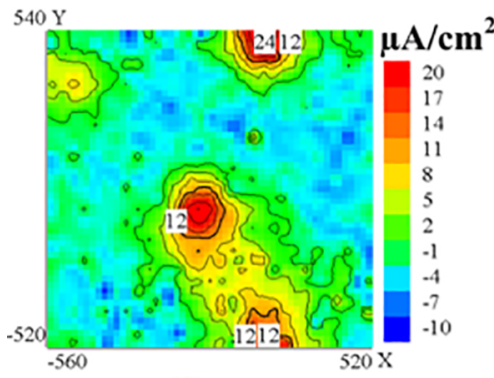

(d)

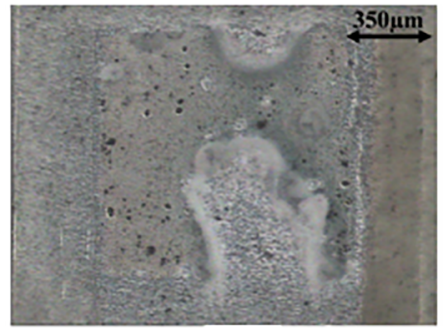

(b)
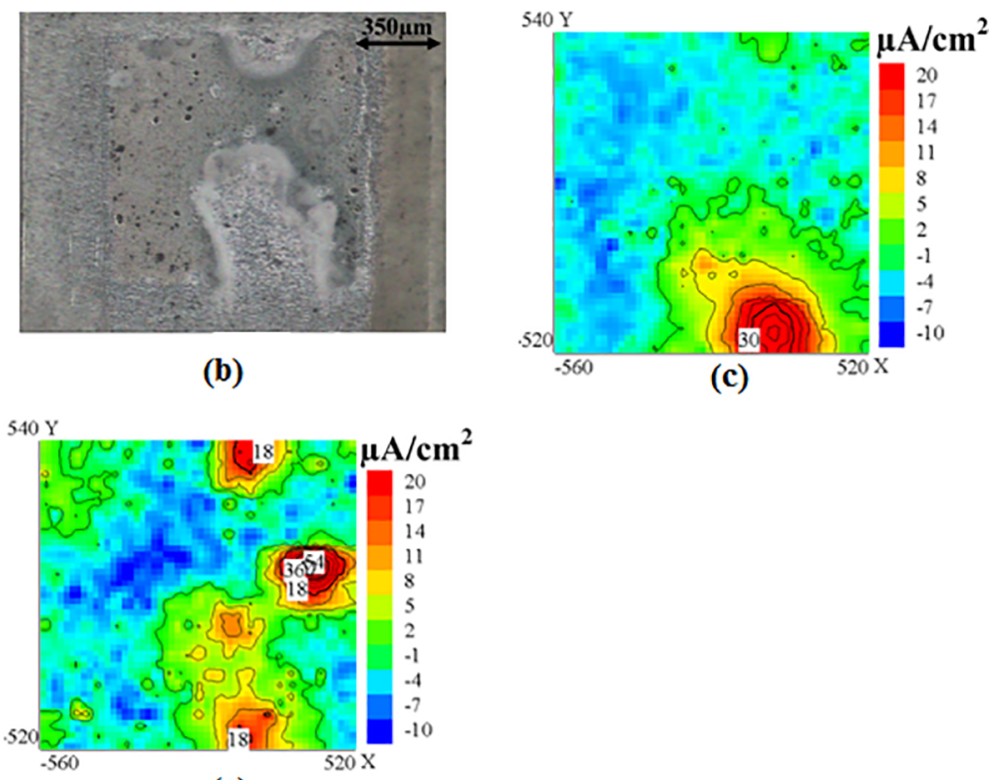

(e)

Figure 7. SVET results along $24 \mathrm{~h}$ immersion in $0.05 \mathrm{~mol} \mathrm{~L}^{-1} \mathrm{NaCl}$ solution. (a) optical micrograph at the beginning of immersion depicting grid points; (b) optical micrograph after 24h of immersion; (c), (d) and (e) current density distributions after $1 \mathrm{~h}, 14 \mathrm{~h}$ and 20 $\mathrm{h}$ of immersion respectively. $\mathrm{X}$ and $\mathrm{Y}$ coordinates represent the length of the mapping in $\mu \mathrm{m}$.

(UFPR), Department of Materials Engineering, University of São Paulo - USP and CQE / Instituto Superior TécnicoUniversity of Lisbon for providing the laboratories facilities, as well as the financial support by Fundação para a Ciência e Tecnologia (FCT) to CQE under contract UID/QUI/ 00100/2013, National Counsel of Technological and Scientific Development (Processes: 303684/2015-1 and 402142/2016-0).

\section{References}

1. Steglich D, Wafai H, Besson J. Interaction between anisotropic plastic deformation and damage evolution in $\mathrm{Al} 2198$ sheet metal. Engineering Fracture Mechanics. 2010;77(17):3501-3518.

2. ASM International. ASM Metals Handbook Volume 2: Properties and Selection: Nonferrous Alloys and Special-Purpose Materials. Materials Park: ASM International; 1990. p. 17-22.

3. Totten GE, Mackenzie DS, eds. Handbook of Aluminum: Volume 1: Physical Metallurgy and Process. Boca Raton: CRC Press; 2003.

4. Shen F, Yi D, Jiang Y, Wang B, Liu H, Tang C, et al. Semi-quantitative evaluation of texture components and fatigue properties in 25244T3 aluminum alloy sheets. Materials Science \& Engineering: $A$. 2016;657:15-25

5. Eskin DG. Decomposition of supersaturated solid solutions in AlCu-Mg-Si alloys. Journal of Materials Science. 2003;38(2):279-290.

6. Ghosh KS, Hilal M, Bose S. Corrosion behavior of 2024 Al-Cu-Mg alloy of various tempers. Transactions of Nonferrous Metals Society of China. 2013;23(11):3215-3227.

7. Queiroz FM, Magnani M, Costa I, de Melo HG. Investigation of the corrosion behaviour of AA2024-T3 in low concentrated chloride media. Corrosion Science. 2008;50(9):2646-2657.
8. Bonfils-Lahovary ML, Lanffont L, Blanc C. Characterization of intergranular corrosion defects in a 2024-T351 aluminium alloy. Corrosion Science. 2017;119:60-67.

9. Gamboni OC, Moreto JA, Bonazzi LHC, Ruchert COFT, Bose Filho WW. Effect of salt-water fog on fatigue crack nucleation of $\mathrm{Al}$ and Al-Li alloys. Materials Research. 2014;17(1):250-254.

10. Chen YQ, Pan SP, Zhou MZ, Yi DQ, Xu DZ, Xu YF. Effects of inclusions, grain boundaries and grain orientations on the fatigue crack initiation and propagation behaviour of 2524-T3 Al alloy. Materials Science \& Engineering: A. 2013;580:150-158.

11. Golden PJ, GrandtAF Jr., Bray GH. A comparison of fatigue crack formation at holes in 2024-T3 and 2524-T3 aluminum alloy specimens. International Journal of Fatigue. 1999;21(Suppl 1):S211-S219.

12. Birbilis N,BuchheitRG. Electrochemical Characteristics of Intermetallic Phases in AluminumAlloys: An Experimental Survey and Discussion. Journal of the Electrochemical Society. 2005;152(4):B140-B151.

13. Birbilis N, Cavanaugh MK, Buchheit RG. Electrochemical behaviour and localized corrosion associated with $\mathrm{Al}_{7} \mathrm{Cu}_{2} \mathrm{Fe}$ particles in aluminum alloy 7075-T651. Corrosion Science. 2006;48(12):4202-4215.

14. Boag A, Hughes AE, Glenn AM, Muster TH, McCulloch D. Corrosion of AA2024T3 Part I: Localised corrosion of isolated IM particles. Corrosion Science. 2011;53(1):17-26.

15. Moreto JA, Marino CEB, Bose Filho WW, Rocha LA, Fernandes JSC. SVET, SKP and EIS study of the corrosion behaviour of high strength $\mathrm{Al}$ and $\mathrm{Al}-\mathrm{Li}$ alloys used in aircraft fabrication. Corrosion Science. 2014;84:30-41.

16. ASTM International. ASTM G61-86(2014) - Standard Test Method for Conducting Cyclic Potentiodynamic Polarization Measurements for Localized Corrosion Susceptibility of Iron-, Nickel-, or CobaltBased Alloys. West Conshohocken: ASTM International; 2014. 
17. Mansfeld F, Fernandes JCS. Impedance spectra for aluminum 7075 during the early stages of immersion in sodium chloride. Corrosion Science. 1993;34(12):2105-2108.

18. Moreto JA, Gamboni OC, Marino CEB, Bose Filho WW, Fernandes JCS, Rocha LA. Corrosion behaviour of Al and Al-Li alloys used as aircraft materials. Corrosão e Protecção de Materiais. 2012;31(3/4):60-64.

19. Moreto JA, Broday EE, Rossino LS, Quites FJ, Fernandes JCS, Bose Filho WW. Effect of Localized Corrosion on Fatigue Crack Growth in 2524-T3 and 2198-T851 Aluminum Alloys Used as Aircraft Materials. Journal of Materials Engineering and Performance. 2018;27(4):1917-1926.

20. Srivatsana TS, Kolara D, Magnusen P. The cyclic fatigue and final fracture behaviour of aluminum alloy 2524. Materials \& Design. 2002;23(2):129-139.

21. Zheng ZQ, Cai B, Zhai T, Li SC. The behaviour of fatigue crack initiation and propagation in AA2524-T3 alloy. Materials Science and Engineering: A. 2011;528(4-5):2017-2022.

22. Gamboni OC. Estudo do efeito do ambiente no comportamento em fadiga de novas ligas de AL de grau aeronáutico. [Dissertation]. São Carlos: University of São Paulo; 2011.

23. Szklarska-Smialowska Z. Pitting corrosion of aluminum. Corrosion Science. 1999;41(9):1743-1767.

24. Buchheit RG. The Electrochemistry of $\theta\left(\mathrm{Al}_{2} \mathrm{Cu}\right), \mathrm{S}\left(\mathrm{Al}_{2} \mathrm{CuMg}\right)$ and $\mathrm{T}_{1}\left(\mathrm{Al}_{2} \mathrm{CuLi}\right)$ and Localized Corrosion and Environment Assisted Cracking in High Strength Al Alloys. Material Science Forum. 2000;331-337:1641-1646.
25. Ferreira SC, Rocha LA, Ariza E, Sequeira PD, Watanabe $\mathrm{Y}$, Fernandes JCS. Corrosion behaviour of $\mathrm{Al} / \mathrm{Al}_{3} \mathrm{Ti}$ and $\mathrm{Al} /$ $\mathrm{Al}_{3} \mathrm{Zr}$ functionally graded materials produced by centrifugal solid-particle method: Influence of the intermetallics volume fraction. Corrosion Science. 2011;53(6):2058-2065.

26. Yasakau KA, Zheludkevich ML, Lamaka SV, Ferreira MGS. Mechanism of Corrosion Inhibition of AA2024 by RareEarth Compounds. The Journal of Physical Chemistry B. 2006;110(11):5515-5528.

27. Ma Y, Zhou X, Huang W, Thompson GE, Zhang X, Luo C, et al. Localized corrosion in AA2099-T83 aluminum-lithium alloy: The role of intermetallic particles. Materials Chemistry and Physics. 2015;161:201-210.

28. Jüttner K. Electrochemical impedance spectroscopy (EIS) of corrosion processes on inhomogeneous surfaces. Electrochimica Acta. 1990;35(10):1501-1508.

29. Kendig MW, Mansfeld F. AC electrochemical impedance of a model pit. Journal of the Electrochemical Society. 1982;129:C318.

30. Ahmed SM. Electrical Double Layer at Metal Oxide- Solution Interfaces. In: Diggle JW, Vijh AK, eds. Oxides and Oxide Films - Volume I. New York: Marcel Dekker; 1972. p. 475

31. Fernandes JCSS. Corrosão por picadas em alumínio modificado por implantação iónica de tungsténio. [PhD Thesis]. Lisbon: Instituto Superior Técnico; 1997.

32. Shi H, Tian Z, Hu T, Liu F, Han EH, Taryba M, et al. Simulating corrosion of $\mathrm{Al}_{2} \mathrm{CuMg}$ phase by measuring ionic currents, chloride concentration and pH. Corrosion Science. 2014;88:178-186. 